\title{
EMMPRIN expression positively correlates with WHO grades of astrocytomas and meningiomas
}

\author{
Wen-Chiuan Tsai $\cdot$ Ying Chen $\cdot$ Li-Chun Huang $\cdot$ \\ Herng-Sheng Lee $\cdot$ Hsin-I Ma $\cdot$ Shih-Ming Huang \\ Huey-Kang Sytwu $\cdot$ Dueng-Yuan Hueng
}

Received: 16 December 2012/ Accepted: 22 June 2013/Published online: 2 July 2013

(C) The Author(s) 2013. This article is published with open access at Springerlink.com

\begin{abstract}
High-grade primary brain tumors possessed poor outcome due to invasiveness. Extracellular matrix metalloproteinase inducer (EMMPRIN) stimulates peritumoral fibroblasts to secrete matrix metalloproteinase and promote invasiveness. This study hypothesized that highgrade brain tumors overexpress EMMPRIN. Analyzing the public delinked database from the Gene Expression Omnibus profile, the results showed that the EMMPRIN mRNA level was higher in WHO grade IV $(n=81)$ than in grade III $(n=19, p<0.0005)$ astrocytomas and nontumor brain tissue controls $(n=23, p<0.00001)$. The results of tissue microarray-based immunohistochemical (IHC) staining revealed that EMMPRIN levels positively correlated with WHO grades for astrocytomas $(p=0.008)$ and meningiomas $(p=0.048)$. EMMPRIN mRNA levels in conventional glioma cell lines $(n=36)$ was not less
\end{abstract}

W.-C. Tsai · H.-S. Lee

Department of Pathology, Tri-Service General Hospital,

National Defense Medical Center, Taipei, Taiwan, ROC

Y. Chen

Department of Biology and Anatomy, National Defense

Medical Center, Taipei, Taiwan, ROC

L.-C. Huang · S.-M. Huang · D.-Y. Hueng

Department of Biochemistry, National Defense Medical Center,

Taipei, Taiwan, ROC

H.-I. Ma · D.-Y. Hueng ( $\bowtie)$

Department of Neurological Surgery, Tri-Service General Hospital, National Defense Medical Center, 325, Sec. 2, Cheng-Kung Road, Neihu, Taipei 114, Taiwan, ROC

e-mail: hondy2195@yahoo.com.tw

H.-K. Sytwu

Department of Microbiology and Immunology,

National Defense Medical Center, Taipei, Taiwan, ROC than those in glioma primary culture cells $(n=27)$ and glioblastoma stem-like cells $(n=12)$. The GBM8401, U87MG, and LN229 human glioma cell lines also overexpressed EMMPRIN. Hematoxylin and eosin, IHC, and immunofluorescence staining of xenografts confirmed that high-grade brain tumors overexpressed EMMPRIN. Lastly, Kaplan-Meier analysis revealed poorer survival in WHO grade IV $(n=56)$ than in grade III astrocytomas $(n=21$, by log-rank test; $p=0.0001,95 \%$ CI: 1.842-3.053). However, in high-grade astrocytomas, there was no difference in survival between high and low EMMPRIN mRNA levels. Thus, this study identified that high-grade brain tumors overexpress EMMPRIN, which positively correlates with WHO grades in human astrocytomas and meningiomas, and suggests that EMMPRIN may be a therapeutic target of brain tumor.

Keywords Astrocytoma - Meningioma - EMMPRIN · GEO profile $\cdot$ WHO grades · Tumor stem-like cells

\section{Introduction}

Astrocytomas and meningiomas are the two most common primary brain tumors (PBTs) [1]. Proper histologic grading is a major predictor of therapeutic effect and prognosis in PBTs [2]. However, the discrepancy between histologic classification and aggressive behavior in meningiomas is around 7-20\% [3]. Therefore, the investigation of biomarkers is very important to bridge the gap. The Gene Expression Omnibus (GEO) profiles [4, 5] provided public delinked database for high-throughput investigation of biomarkers.

Matrix metalloproteinases degrade all of the molecules of the extracellular matrix (ECM) [6]. Activation of MMPs 
greatly affects cell-matrix interaction, angiogenesis, and the inflammatory process [7-9]. Extracellular MMP inducer (EMMPRIN), also called CD147 or basigin (BSG), is a $55-\mathrm{kDa}$ molecule expressed on the tumor cell surface that plays important roles in the up-regulation of peri-tumoral fibroblasts [10]. EMMPRIN is also an inducer of MMP-1, MMP-2, and MMP-3 [6, 11]. Recent studies have shown that ECM degradation may be related to tumor invasion, progression, and even metastasis [12]. Thus, EMMPRIN overexpression is seen in many human cancers, including oral [13], laryngeal [14], esophageal [15], breast [16], ovarian [17], cervical [18], hepatic [19], kidney [20], colorectal carcinomas [21], and $\mathrm{T}$ cell lymphomas [22]. EMMPRIN on the surface of glioma cells may also strengthen tumor progression [23, 24], but the possible role of EMMPRIN in meningiomas remains unknown.

The present study hypothesized that high-grade brain tumors overexpress EMMPRIN. Using the GEO profiles, EMMPRIN expressions in PBTs were investigated and correlated with World Health Organization (WHO) grades and survival. Immunohistochemical (IHC) staining of tissue microarray and xenografts were used to validate the database findings. This study posited that a simple strategy of combined bioinformatics and wet lab approaches can be used to identify potential biomarkers in human brain tumors.

\section{Materials and methods}

Analyses of functional genomic databases

The EMMPRIN mRNA expression was obtained from the GDS1962/208677_s_at/BSG database. http://www.ncbi. nlm.nih.gov/geo/tools/profileGraph.cgi?ID=GDS1962:208 677_s_at. The sample size and WHO grades enrolled in this GDS1962 dataset was described previously [25]. The survival data of 77 primary high-grade astrocytomas (WHO grades III and IV) obtained from the GDS1815 database (http://www.ncbi.nlm.nih.gov/geo/tools/profile Graph.cgi?ID=GDS1815:208677_s_at) and devoted by Phillips et al. [26]. The GDS3885 database included 36 panels of conventional glioma cell lines data, 12 panels of glioma primary culture cells data, and 27 panels of glioma stem-like cells data (http://www.ncbi.nlm.nih.gov/geo/ tools/profileGraph.cgi?ID=GDS3885:208677_s_at). The background of cell line was described previously [27].

Construction of tissue microarray

The Institutional Review Board of Tri-Service General Hospital, National Defense Medical Center approved this study. Tissue microarray slides were constructed from 103 paraffin-embedded tissues, including 59 cases of meningiomas, 41 cases of astrocytomas, and 3 non-neoplastic brain tissues. For slide construction, one core (2 $\mathrm{mm}$ in diameter) was taken from a selected area of each paraffin-embedded tumor tissue. Both the tissue microarray scores and the corresponding paraffin-embedded specimens were uniformly stained. Pathologic diagnosis in these cases was reviewed by at least two experienced pathologists. The histo-pathologic differentiation of brain tumors was determined according to the criteria of the WHO classification of tumor [28]. None of the astrocytomas and meningiomas included in this study ever received radiotherapy or chemotherapy before surgery.

Immunohistochemical (IHC) staining

Tissue microarray sections and xenografts were processed following previous protocol [2], incubated with a polyclonal rabbit anti-human EMMPRIN antibody (1:200 diluted in phosphate buffered saline [PBS]; Bioss, Woburn, MA, USA) for $1 \mathrm{~h}$ at room temperature, washed 3 times (each for $5 \mathrm{~min}$ in PBS), incubated with biotin-labeled secondary immunoglobulin (1:100, DAKO, Glostrup, Denmark) for $1 \mathrm{~h}$ at room temperature, washed 3 times, and treated with 3-amino-9-ethylcarbazole substrate chromogen (DAKO, Glostrup, Denmark) at room temperature to visualize peroxidase activity. Sections of poorly differentiated hepatocellular carcinoma tissue (known to stain positive for EMMPRIN) were used as positive control and non-neoplastic liver were used as negative control [19].

\section{Assessment of EMMPRIN immuno-staining scores}

To evaluate immuno-reactivity and histologic appearance, all tissue microarray experiments were repeated two times and the slides were examined and scored by two investigators concurrently. To assess EMMPRIN immuno-staining scores, the intensity of cytoplasmic and membranous staining was scored as 0 (absence of staining), 1 (weak staining), 2 (moderate staining), or 3 (strong staining). Weak, moderate, and strong cytoplasmic stainings were identified by microscopy with magnification of $40 \times, 20 \times$, and $10 \times$ or $4 \times$, respectively [29]. The cut-off value of EMMPRIN intensity scores was set by the magnification of objective lens. The percentage of tumor staining was scored $0(<5 \%), 1(5-25 \%), 2(25-50 \%), 3(50-75 \%)$, and $4(75-100 \%)$. The EMMPRIN immuno-staining scores of human astrocytomas and meningiomas were defined by calculating the intensity score and multiplying it by the corresponding percentage score. EMMPRIN immuno-staining scores ranged from 0 to 12 , including 0 , $1,2,3,4,6,8,9$, and 12 . 
Cell lysate preparation and Western blots

GBM8401, U87MG, LN229, and HepG2 were maintained in Dulbecco's modified Eagle's medium (DMEM) containing $10 \%$ fetal bovine serum (FBS), penicillin, and streptomycin. Cell lysates prepared from $2 \times 10^{7}$ GBM8401, U87MG, LN229 glioma cells, and HepG2 hepatoma cell line (positive control) were used for Western blot analysis of EMMPRIN, with $\alpha$-actin (Santa Cruz) as internal control following previous protocol [30].

In vivo orthotopic xenograft

The Institutional Animal Care and Use Committee of National Defense Medical Center, Taipei, Taiwan (IACUC-13-147) approved the study of xenografts. The experimental procedures of in vivo orthotopic xenograft were as described previously [25, 30-32]. Briefly, $5 \times 10^{5}$ cells were injected into the right cerebral hemisphere of BALB/cAnN.Cg-Foxn1nu/CrlNarl nude mice. Gliomas were permitted to grow in the murine brain.

Immunofluorescence (IF) staining

After deparaffinization and rehydration, the tumor samples were rinsed with PBS. For antigen retrieval, the samples were heated by a microwave oven in citrate buffer $(10 \mathrm{mM}$ Citric Acid, pH 6.0) for $15 \mathrm{~min}$. After cooling for $15 \mathrm{~min}$, blocking solution $(5 \%$ non-fat milk in $0.1 \%$ Triton $\mathrm{X}-100)$ was applied to block non-specific binding at room temperature for $30 \mathrm{~min}$. Then, primary antibody (EMMPRIN) dissolved in PBS with $5 \%$ non-fat milk was added to the samples at $4{ }^{\circ} \mathrm{C}$ overnight. The next day, the samples were rinsed with PBS and secondary antibody-conjugated FITC and DAPI (Sigma) were applied at room temperature for $1 \mathrm{~h}$ and $15 \mathrm{~min}$, respectively. The samples were mounted (Gel mount Aqueous, Sigma) and the slides were examined by microscopy and photographed (Leica).

\section{Statistical analysis}

All results were expressed as mean \pm standard deviation (SD).The correlations between variables of immunostaining scores were calculated by the Pearson Product Moment Method. Student's two-tailed t test was used to determine differences in means between any two groups in EMMPRIN mRNA levels of different WHO grades of human astrocytoma samples. SigmaState software (Jandel Scientific, USA) was also used to perform linear regression testing to analyze the relationships between EMMPRIN expression and WHO grades of astrocytomas and meningiomas. Survival cures were analyzed using the Kaplan-
Meier method, while differences in survival distributions were investigated by log-rank test. Statistical significance was set at $p<0.05$.

\section{Results}

GEO identified the candidate biomarker EMMPRIN mRNA level and correlated it with WHO grades in human astrocytomas

The GDS1962 dataset and statistical analyses were used to investigate the correlation between EMMPRIN mRNA and WHO grades (Fig. 1a). In samples with different pathologic grades, EMMPRIN mRNA level was higher in WHO grade IV $(n=81)$ than in grade III $(n=19)(p<0.0005)$ human astrocytomas and non-tumor brain tissue controls $(n=23)(p<0.00001$, Student's $t$ test $)$.

Tissue microarray provided the platform to identify EMMPRIN and correlate with WHO grades in human astrocytomas

Only weak stain and limited percentage of non-neoplastic brain tissues were expressed by the IHC staining of EMMPRIN (average immuno-staining scores, $0.5 \pm 0.4$ ). Compared to non-neoplastic brain tissues, most astrocytomas had significantly higher expressions of EMMPRIN. Moreover, the IHC staining intensity and average percentage of tumor staining in anaplastic astrocytomas (average score, $7.3 \pm$ 3.0) and glioblastoma multiforme (average score, $7.8 \pm 2.1$ ) were higher than in pilocytic astrocytomas (average score, $1.5 \pm 0.5$ ) and diffuse astrocytomas (average score, $2.0 \pm$ 1.3). Increased EMMPRIN expression positively correlated with WHO grade of astrocytomas $(p=0.008)$ (Fig. 1a, b, $\mathrm{d}-\mathrm{k}$; Table 1).

Tissue microarray provided the platform to identify EMMPRIN and correlate with WHO grades in human meningiomas

The IHC staining intensity, percentage of meningioma expression, and total immuno-staining scores of EMMPRIN were shown in Table 1. Most meningiomas showed higher EMMPRIN immuno-staining scores compared to non-tumor brain tissues. Furthermore, the intensity and immuno-staining scores of EMMPRIN in atypical meningiomas $(5.0 \pm 1.8)$ and anaplastic meningiomas (6.6 \pm 3.1) were higher than that of meningothelial meningiomas $(1.3 \pm 0.6)$. The immuno-staining scores of EMMPRIN significantly correlated with WHO grades of meningiomas $(p=0.048)$ (Fig. 1c, l-s; Table 1). 


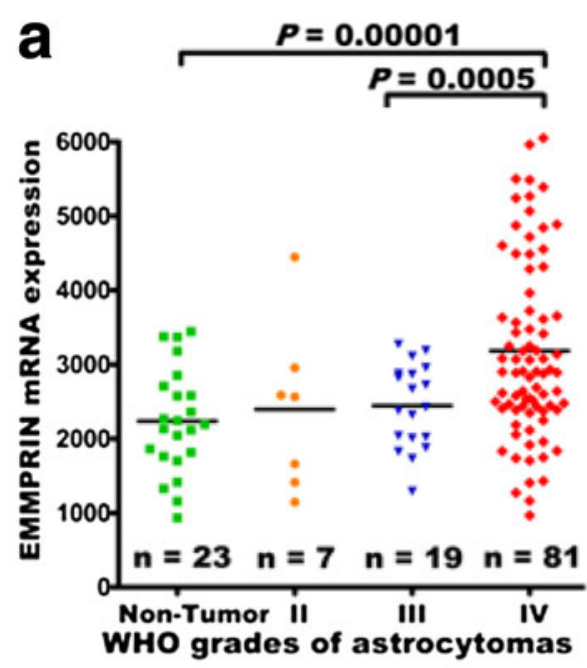

b

C
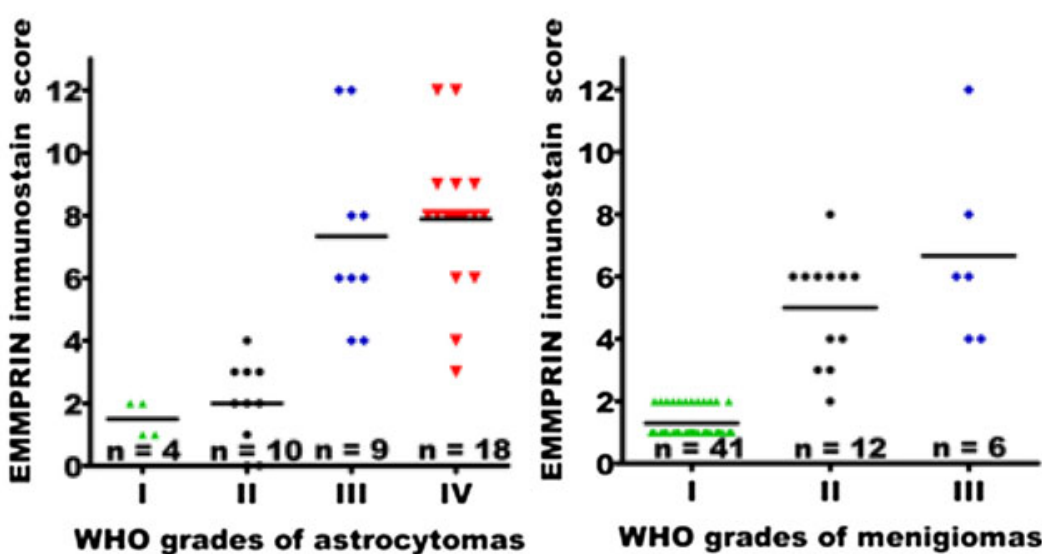

Astrocytomas
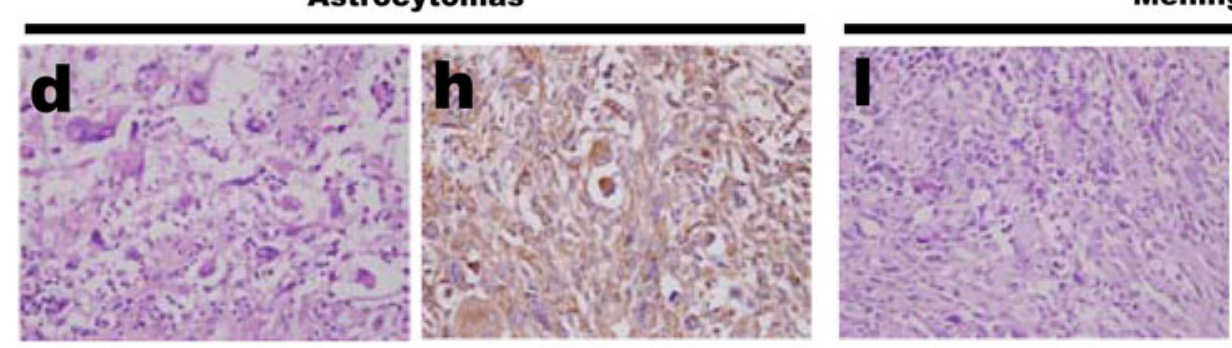

Meningiomas
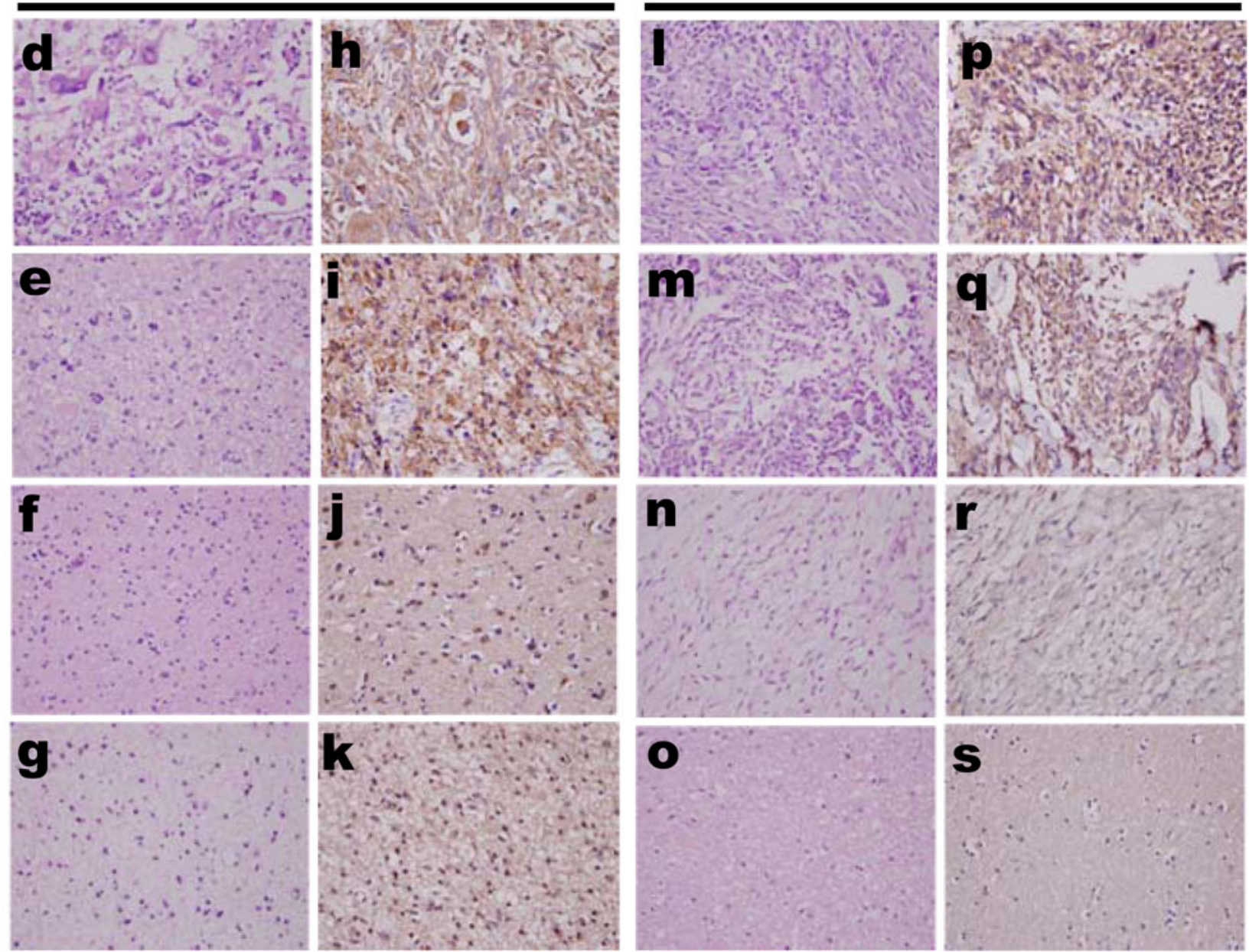

Fig. 1 Expression of EMMPRIN in human astrocytomas and meningiomas. a EMMPRIN mRNA levels were significantly higher in grade IV than grade III $(p=0.0005)$ primary astrocytomas patient samples and non-tumor controls $(p=0.00001)$. b, $\mathbf{c}$ By immunostain score, EMMPRIN positively correlated with WHO grades in human astrocytomas $(p=0.008)$, and meningiomas $(p=0.048$, by Pearson product method correlation test), respectively. Representative hematoxylin and eosin staining of $\mathbf{d}$ glioblastomas multiforme, $\mathbf{e}$ anaplastic

astrocytomas, $\mathbf{f}$ diffuse astrocytomas, and $\mathbf{g}$ pilocytic astrocytomas. Immuno-histochemical staining of EMMPRIN in $\mathbf{h}$ glioblastomas multiforme, $\mathbf{i}$ anaplastic astrocytomas, $\mathbf{j}$ diffuse astrocytomas, and $\mathbf{k}$ pilocytic astrocytomas. Representative hematoxylin and eosin staining of $\mathbf{I}$ anaplastic, $\mathbf{m}$ atypical, $\mathbf{n}$ meningothelial meningiomas, and $\mathbf{o}$ non-neoplastic brain tissues. Immuno-histochemical staining of EMMPRIN in $\mathbf{p}$ anaplastic, $\mathbf{q}$ atypical, $\mathbf{r}$ meningothelial meningiomas, and $\mathbf{s}$ non-neoplastic brain tissues. Original magnification $\times 400$ 
Table 1 The immunohistochemical staining scores of EMMPRIN in various WHO grades of astrocytomas and meningiomas

\begin{tabular}{|c|c|c|c|c|c|}
\hline & $\begin{array}{l}\text { Case } \\
\text { numbers }\end{array}$ & $\begin{array}{l}\text { Average intensity } \\
\text { score } \\
\text { (means } \pm \\
\text { standard error) }\end{array}$ & $\begin{array}{l}\text { Average percentage } \\
\text { score (means } \pm \\
\text { standard error) }\end{array}$ & $\begin{array}{l}\text { Average immunostain } \\
\text { score } \\
\text { (means } \pm \\
\text { standard error) }\end{array}$ & Correlation $^{\mathrm{a}}$ \\
\hline Non-neoplastic brain tissue ${ }^{\mathrm{b}}$ & 3 & $0.3 \pm 0.2$ & $0.5 \pm 0.3$ & $0.5 \pm 0.4$ & \\
\hline \multicolumn{6}{|l|}{ WHO grades of astrocytomas } \\
\hline $\begin{array}{l}\text { Pilocytic astrocytoma, WHO } \\
\text { grade I }\end{array}$ & 4 & $0.8 \pm 0.3$ & $1.5 \pm 0.6$ & $1.5 \pm 0.5$ & \multirow[t]{4}{*}{$\begin{array}{l}\text { Positive correlation } \\
\quad\left(p=0.008^{*}\right)\end{array}$} \\
\hline $\begin{array}{l}\text { Diffuse astrocytoma, WHO } \\
\text { grade II }\end{array}$ & 10 & $1.1 \pm 0.8$ & $1.4 \pm 0.5$ & $2.0 \pm 1.3$ & \\
\hline $\begin{array}{l}\text { Anaplastic astrocytomas, WHO } \\
\text { grade III }\end{array}$ & 9 & $2.6 \pm 1.3$ & $2.8 \pm 1.1$ & $7.3 \pm 3.0$ & \\
\hline $\begin{array}{l}\text { Glioblastoma multiforme WHO } \\
\text { grade IV }\end{array}$ & 18 & $2.5 \pm 1.2$ & $3.1 \pm 0.9$ & $7.8 \pm 2.1$ & \\
\hline \multicolumn{6}{|l|}{ WHO grades of meningiomas } \\
\hline Meningiomas, WHO grade I & 41 & $0.8 \pm 0.4$ & $1.2 \pm 0.5$ & $1.3 \pm 0.6$ & \multirow{3}{*}{$\begin{array}{l}\text { Positive correlation } \\
\quad\left(p=0.048^{*}\right)\end{array}$} \\
\hline $\begin{array}{l}\text { Atypical meningiomas, WHO } \\
\text { grade II }\end{array}$ & 12 & $1.8 \pm 0.8$ & $2.9 \pm 1.2$ & $5.0 \pm 1.8$ & \\
\hline $\begin{array}{l}\text { Anaplastic meningiomas, WHO } \\
\text { grade III }\end{array}$ & 6 & $2.1 \pm 1.4$ & $3.1 \pm 1.4$ & $6.6 \pm 3.1$ & \\
\hline
\end{tabular}

EMMPRIN Extracellular matrix metalloproteinase inducer, WHO World Health Organization

* Means statistical significance

a The correlation was analyzed by Pearson Product Method Correlation test

b These three non-neoplastic brain tissues were taken from non-tumor part of diffuse astrocytomas (WHO grade II)

In vitro validation using GEO bioinformatics analysis of the EMMPRIN mRNA expression in glioma cell lines

Using the GDS3885 database, the EMMPRIN mRNA expression in conventional glioma cell lines, glioma primary culture cells, and glioma stem-like cells were analyzed. There was no significant difference among conventional glioma cell lines $(n=36)$, glioma primary culture cells $(n=27)$, and glioblastoma stem-like cells $(n=12)$ from human primary brain gliomas (Fig. 2a-c). This suggests that glioma cell lines recapitulate transcriptional features of gliomas, thereby allowing the investigation of therapeutic candidates.

Serial passages on alterations of EMMPRIN, EST1, and p16 mRNA expression profiles

Regarding the GDS3885 database, eight pairs of serial passages data were achieved from the early and late passages of glioma stem-like cells. EMMPRIN mRNA expression decreased in six of the eight pairs $(75 \%)$, including GS-1, GS-3, GS-5, GS-7, GS-8, and GS-9 when comparing the early with the late passages (Fig. 2d). Since serial passage decreased the amount and length of telomeric DNA in human fibroblasts [33], the mRNA expression of telomere-regulated genes was further checked. Ever shorter telomeres protein 1 (EST1) [34] was one of the telomere-regulated sub-units directly involved in telomere replication and correlated with telomerase. Analyses of EST1 showed higher EST1 in early passage than in late passage (Fig. 2e). Since the reduction of telomere length led to senescence, the p16 belonged to the senescence-regulated gene [35]. Further investigation of the mRNA expression of p16 revealed that later passage expressed higher level of p16 than early passage in four of six glioma stem-like cells, including GS-3, GS-5, GS-8, and GS-9 (Fig. 2f), suggesting the serial passage-induced senescence of gliomas.

In vitro validation using Western blot analysis confirmed the overexpression of EMMPRIN in glioma cells

To determine the EMMPRIN protein production in human glioma cell line, Western blots showed that EMMPRIN protein production was overexpressed in human glioma cell lines (Fig. 3a) and was higher in GBM8401 than in U87MG, or LN229 glioma cell lines. The high EMMPRINexpressing GBM8401 was then used for further xenograft study. 
a
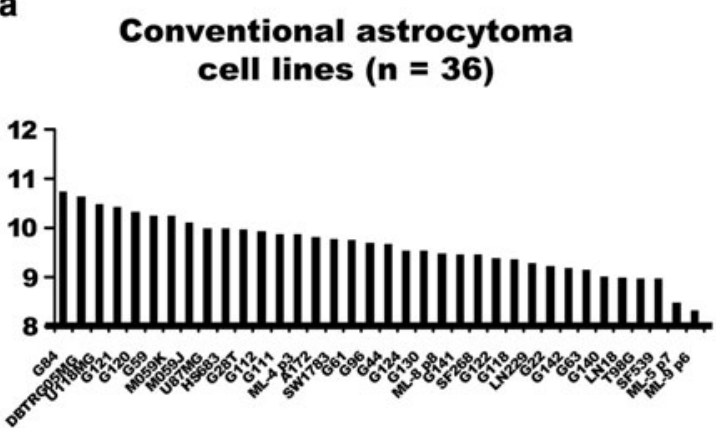

b

\section{Glioblastoma stem-like cells $(n=27)$}

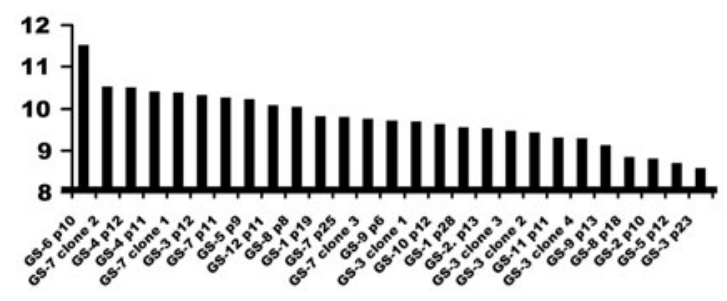

C

\section{Astrocytoma primary culture cells $(n=12)$}

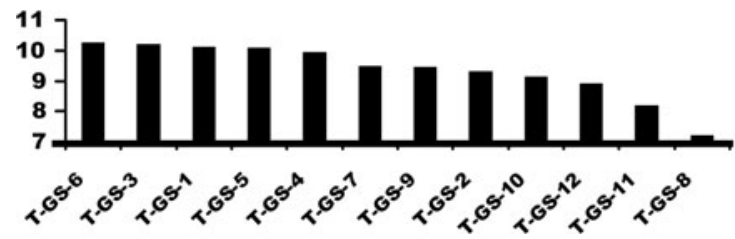

Fig. 2 Comparison of the EMMPRIN mRNA expressions among a conventional astrocytoma cell lines $(n=36)$, b glioblastoma stemlike cells $(n=27)$, and $\mathbf{c}$ astrocytoma primary culture cells $(n=12)$ from GDS3885 dataset of GEO profile. Glioma cell lines recapitulated the transcriptional value of EMMPRIN in the above three types

Immunohistochemical and immunofluorescence staining of xenograft confirmed EMMPRIN overexpression in high-grade astrocytomas

The GBM8401-xenograft formed glioma mass in the right hemisphere, with invasive glioma tumor islands (Fig. 3b, c) after 2-week inoculation. The high EMMPRINexpressing glioma cells also displayed a highly invasive phenotype, with invasive glioma islands growing away from the original xenograft site (Fig. 3d). In contrast, the normal control of astrocytes and endothelial cells showed low-EMMPRIN expression, while oligodendrocytes were negative for EMMPRIN staining (Fig. 3e-g). The high EMMPRIN-expressing glioma cells were further identified via IF staining with antibodies specific for EMMPRIN. The FITC-labeled EMMPRIN-expressing GBM8401 glioma cells were distributed near the invasive front at the tumorbrain interface with some invasive tumor islands away
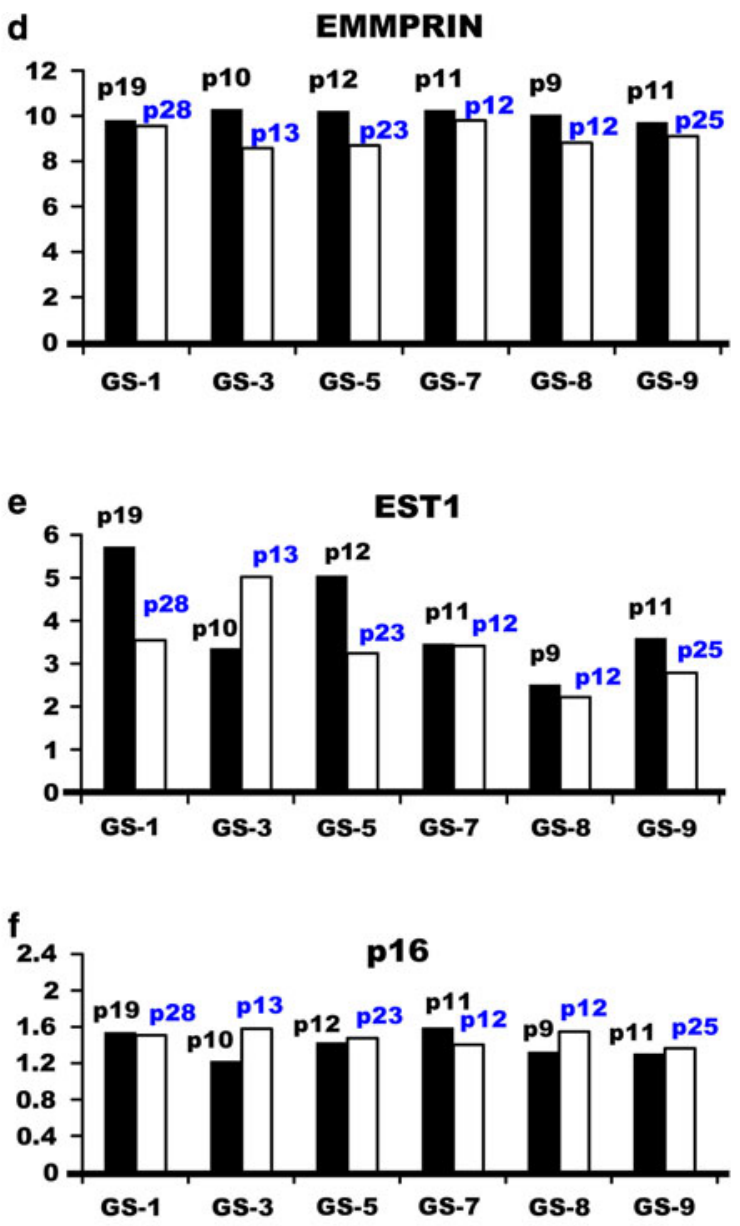

of glioma cells. d-f Alterations of EMMPRIN, EST1, and p16 mRNA expressions after serial passages. The mRNA expression in serial passages of glioma-stem like cells showed decreased EMMPRIN and EST1, but increased p16 when comparing early to late passages

from the glioma main tumor mass, compared to the contralateral normal control of brain astrocytes that showed only faint FITC fluorescence (Fig. 3h-m). Based on these evidences, high-grade brain tumors overexpressed EMMPRIN.

Relationships of EMMPRIN mRNA to survival of highgrade astrocytomas

Using the GDS1962 database, survival analysis was achieved from 77 public delinked databases. The median survival time in patients with WHO grade III and grade IV astrocytomas was 175 and 71.5 weeks, respectively. Kaplan-Meier post-operative survival analysis was applied to investigate the relationship between overall survival of patients with high grade astrocytomas and EMMPRIN mRNA levels. Overall survival was poor in patients with WHO grade IV $(n=56)$ than WHO grade III astrocytomas 


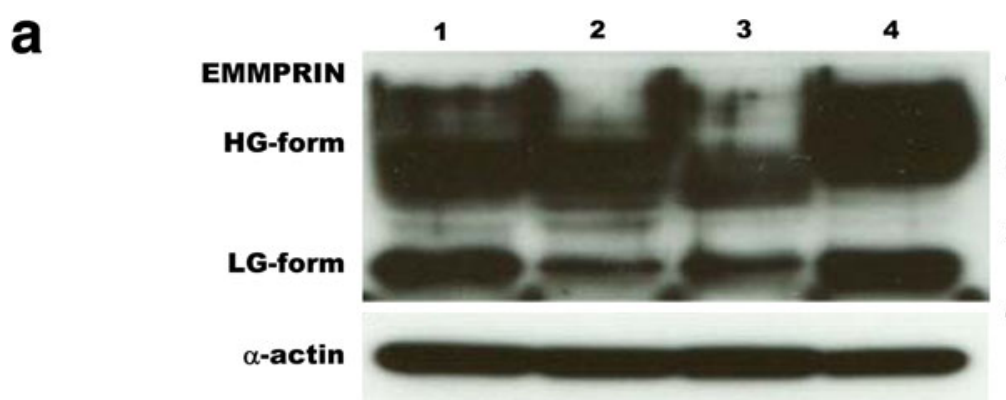

\section{GBM8401}

2. U87MG

3. LN229

4. HepG2
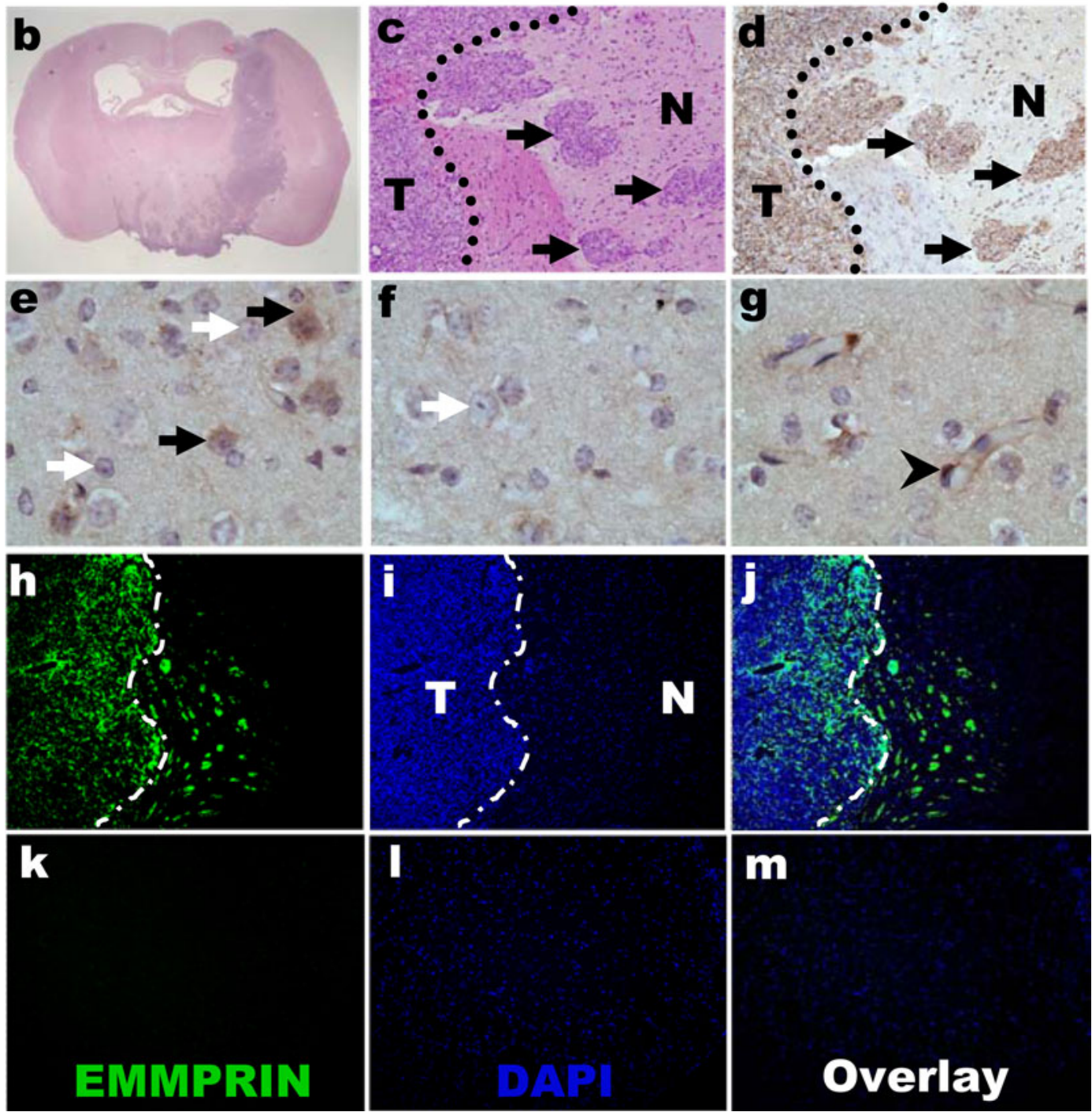

Fig. 3 Western blot analysis of astrocytomas cell lines, and histopathologic staining of EMMPRIN-expressing in GBM8401 glioma xenografts. a Western blot analysis of EMMPRIN expression in GBM8401, U87MG, LN229 glioma cells, and positive control HepG2 hepatoma cell line. EMMPRIN protein production consisted of $H G$ high glycosylation, and $L G$ low glycosylation forms. The expression of $\alpha$-actin was used as internal control. Hematoxylin and eosin staining of GBM8401 glioma xenograft in b coronal section of the brain and $\mathbf{c}$ tumor-brain interface. $\mathbf{d}$ Immuno-histochemical staining revealed EMMPRIN-expressing invasive tumor islands (black arrows). e-g The normal control of astrocytes (black arrows), oligodendrocytes (white arrows), and endothelial cells (black arrow $h e a d)$. In the immuno-fluorescence staining with antibodies specific for EMMPRIN, h FITC-labeled EMMPRIN-expressing GBM8401 glioma cells were distributed near the invasive front at the tumorbrain interface (dash line) with some invasive tumor islands away from the main tumor mass. $\mathbf{k}$ The contralateral normal control of brain astrocytes showed only faint FITC fluorescence. i, l DAPIstained nuclei. j, $\mathbf{m}$ The merged photos of FITC-labeled EMMPRIN expressing tumors and DAPI-stained nuclei. Original magnification $\times 100$. Data were representative of three independent experiments. $T$ tumor, $N$ neighborhood brain parenchyma. Original magnification $\times 12.5(\mathbf{b}) ; \times 200(\mathbf{c}, \mathbf{d}) ; \times 1,000$ in $(\mathbf{e}-\mathbf{g})$; and $\times 100(\mathbf{h}-\mathbf{m})$. (Color figure online) 

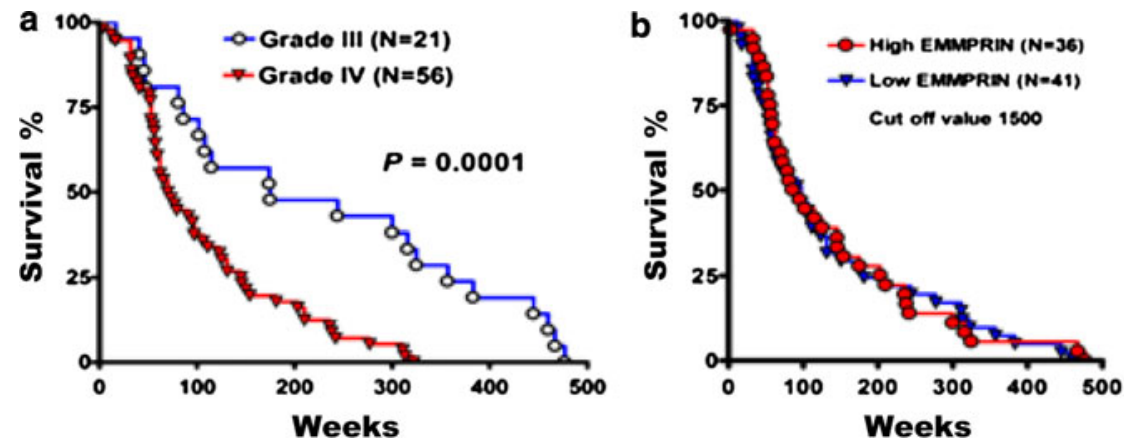

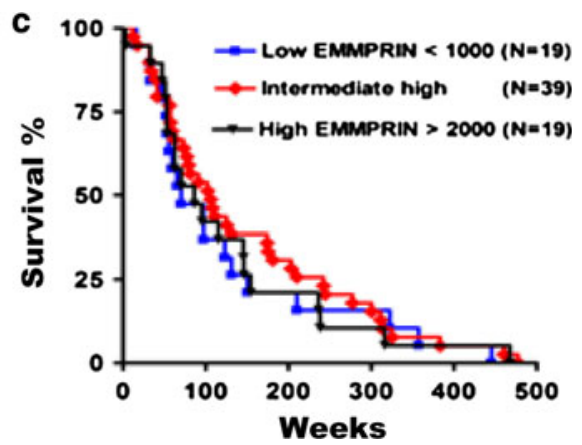

Fig. 4 Kaplan-Meier survival analyses of high grade astrocytomas. a Survival patterns in patients with WHO grade IV $(n=56)$ compared to those with WHO grade III $(n=21)$ high-grade astrocytomas $(p=0.0001$, by log-rank test). b Patterns of patients with high EMMPRIN $(>1,500, n=36)$ versus low EMMPRIN

$(n=21) \quad(p=0.0001, \quad$ by log-rank test; $95 \% \quad \mathrm{CI}$ : 1.842-3.053) (Fig. 4a). This result consistently indicated that the GDS1962 database was a reliable positive control for survival analysis.

The cut-off value was then set up at 1,500, or the point of median EMMPRIN gene expression value. The median survival time of patients with low and high EMMPRIN expressions was 97 and 90.5 weeks, respectively. Patients with high-grade astrocytomas and high EMMPRIN mRNA levels $(n=36)$ did not have worse overall survival than patients with low EMMPRIN mRNA expression $(n=41)$ ( $p=0.7274$, by log-rank test; $95 \%$ CI: 0.4327-1.711) (Fig. 4b). Kaplan-Meier post-operative survival analysis did not show any statistical significance when the cut-off value of EMMPRIN expression was set to low $(<1,000$, $n=19)$, intermediate $(1,000-2,000, n=39)$, and high $(>2,000, n=19)$ (Fig. 4c).

\section{Discussion}

This study validates a simple strategy using GEO bioinformatics and wet lab approaches to identify the biomarker, EMMPRIN, in human brain tumors. Li et al. [36] investigated EMMPRIN (also known as CD147) mRNA expression and IHC in 50 cases and found that EMMPRIN expression levels were apparently elevated in high-grade astrocytomas. This was consistent with the finding of the present study. Their study also found that higher expression of EMMPRIN was associated with poor survival time in their astrocytoma patient cohort. In contrast, regarding the stratification of EMMPRIN gene expression level, KaplanMeier survival analysis of the GDS1815 database showed no statistical difference in 77 primary high grade astrocytomas, suggesting that EMMPRIN was not the only factor that played a role in determining outcome. Other factors, such as nodal and osteopontin, are also important
$(<1,500, n=41)$ expressions ( $p=0.7274$, by log-rank test). c Patterns of patients with high EMMPRIN $(>2,000, n=19)$ versus intermediate high $(n=39)$ and low EMMPRIN $(<1,000, n=19)$ expressions $(p=0.6981$, by log-rank test)

contributors to invasiveness and survival in astrocytomas $[25,30,32]$. The other possible explanations include the limitation of patient populations that only involved highgrade, but not low-grade, controls.

Complete resections of meningiomas and tumor bed meninges have the advantage of reducing recurrence in benign or atypical meningiomas, but the results are not satisfactory [37]. This suggests that there are still other molecular factors like EMMPRIN and MMPs aiding tumor cell invasion to move away from the main tumor mass and infiltrate the normal brain parenchyma, leading to tumor recurrence.

The paradigm of tumor stem-like cells has been established in human astrocytomas [31] and meningiomas [3841]. Human glioma cells exhibit radio-resistance and higher colony formation ability in CD133-expressed glioma sub-populations [31]. Consistently, human meningioma stem-like cells display chemotherapeutic resistance, radiation resistance, high tumorigenicity, and infiltration into the surrounding normal brain parenchyma [40]. One of the interesting findings is the trend of EMMPRIN mRNA expression decreasing in $75 \%$ of serial passages of glioma stem-like cells. It has been reported that in vitro serial passage decreases the amount and length of telomeric DNA in human fibroblasts [33]. Further analyzing EST1, one of the telomere-regulated sub-units, showed that early passage display higher EST1 than late passage, consistent with the serial passage effect. Other possible reasons include senescence. Investigation of p16 revealed that later passage expressed higher p16 level than early passage in $75 \%$ of glioma stem-like cells, suggesting the serial passageinduced senescence of gliomas. Overexpression of p16 induces senescence and cell cycle arrest to suppress the invasion and proliferation of human glioma cell lines U87MG and U373 MG. The p16-overexpressed glioma cells are positive for senescence-associated beta-galactosidase staining and enlarged morphology [35]. 
It is difficult to obtain the hundred number scales of fresh or frozen samples from human brain tumors, especially for low-grade astrocytomas, to analyze the mRNA expression or protein level. Instead, using the GEO profile provides an enormous public delinked database for the investigation of molecular cell biology of human brain astrocytomas [5, 25]. However, there are still some limitations inherent to this study. One database alone cannot provide all the information at the same time for investigating mRNA gene expression, protein level, survival time, and clinico-pathologic parameters. To overcome this, multiple databases, including GDS1962, GDS3885, and GDS1815, were used. In meningiomas, limited by the tissue sample amount and GEO database source, the mRNA expression, survival, and cell line data were not obtained in this study. Instead, tissue microarray-based immuno-histochemical staining provided immuno-staining score for study of meningioma samples. Sufficient human meningioma samples in future studies are warranted to allow extensive studies of EMMPRIN.

\section{Conclusions}

This study demonstrates a simple strategy of using GEO bioinformatics and wet lab approaches to identify potential biomarkers in human brain tumors. High-grade brain tumors overexpress EMMPRIN and EMMPRIN expression positively correlates with WHO grades in human astrocytomas and meningiomas, suggesting that EMMPRIN may be a therapeutic target of brain tumor. Future geneticmodified tumor cell manipulation, such as silencing EMMPRIN, may identify the role of EMMPRIN in modulating invasiveness and the underlying signaling pathway.

Acknowledgments This study was supported in part by grants from the Tri-Service General Hospital, National Defense Medical Center, Taipei, Taiwan, ROC (TSGH-C101-009-S05, TSGH-C102-073, and TSGH-C102-007-009-S05).

Open Access This article is distributed under the terms of the Creative Commons Attribution License which permits any use, distribution, and reproduction in any medium, provided the original author(s) and the source are credited.

\section{References}

1. Wrensch M, Minn Y, Chew T, Bondy M, Berger MS (2002) Epidemiology of primary brain tumors: current concepts and review of the literature. Neuro-oncology 4:278-299

2. Tseng KY, Chung MH, Sytwu HK, Lee HM, Chen KY, Chang C, Lin CK, Yen CH, Chen JH, Lin GJ, Ma HI, Yeh YS, Ju DT, Liu MY, Hueng DY (2010) Osteopontin expression is a valuable marker for prediction of short-term recurrence in WHO grade I benign meningiomas. J Neurooncol 100:217-223. doi: 10.1007/s11060-010-0164-2

3. Vankalakunti M, Vasishta RK, Das Radotra B, Khosla VK (2007) MIB-1 immunolabeling: a valuable marker in prediction of benign recurring meningiomas. Neuropathology 27:407-412

4. Barrett T, Wilhite SE, Ledoux P, Evangelista C, Kim IF, Tomashevsky M, Marshall KA, Phillippy KH, Sherman PM, Holko M, Yefanov A, Lee H, Zhang N, Robertson CL, Serova N, Davis S, Soboleva A (2013) NCBI GEO: archive for functional genomics data sets-update. Nucleic Acids Res 41:D991-D995. doi:10.1093/nar/gks1193

5. Barrett T, Troup DB, Wilhite SE, Ledoux P, Rudnev D, Evangelista C, Kim IF, Soboleva A, Tomashevsky M, Marshall KA, Phillippy KH, Sherman PM, Muertter RN, Edgar R (2009) NCBI GEO: archive for high-throughput functional genomic data. Nucleic Acids Res 37:D885-D890. doi:10.1093/nar/gkn764

6. Gabison EE, Mourah S, Steinfels E, Yan L, Hoang-Xuan T, Watsky MA, De Wever B, Calvo F, Mauviel A, Menashi S (2005) Differential expression of extracellular matrix metalloproteinase inducer (CD147) in normal and ulcerated corneas: role in epithelio-stromal interactions and matrix metalloproteinase induction. Am J Pathol 166:209-219. doi:10.1016/S0002-9440 (10)62245-6

7. Sivak JM, Fini ME (2002) MMPs in the eye: emerging roles for matrix metalloproteinases in ocular physiology. Prog Retin Eye Res 21:1-14

8. Kahari VM, Saarialho-Kere U (1997) Matrix metalloproteinases in skin. Exp Dermatol 6:199-213

9. Visse R, Nagase H (2003) Matrix metalloproteinases and tissue inhibitors of metalloproteinases: structure, function, and biochemistry. Circ Res 92:827-839. doi:10.1161/01.RES.0000070112. 80711.3D

10. Biswas C, Zhang Y, DeCastro R, Guo H, Nakamura T, Kataoka H, Nabeshima K (1995) The human tumor cell-derived collagenase stimulatory factor (renamed EMMPRIN) is a member of the immunoglobulin superfamily. Cancer Res 55:434-439

11. Kataoka H, DeCastro R, Zucker S, Biswas C (1993) Tumor cellderived collagenase-stimulatory factor increases expression of interstitial collagenase, stromelysin, and 72-kDa gelatinase. Cancer Res 53:3154-3158

12. Liotta LA, Steeg PS, Stetler-Stevenson WG (1991) Cancer metastasis and angiogenesis: an imbalance of positive and negative regulation. Cell 64:327-336

13. Bordador LC, Li X, Toole B, Chen B, Regezi J, Zardi L, Hu Y, Ramos DM (2000) Expression of emmprin by oral squamous cell carcinoma. International journal of cancer Journal international du cancer 85:347-352

14. Rosenthal EL, Shreenivas S, Peters GE, Grizzle WE, Desmond R, Gladson CL (2003) Expression of extracellular matrix metalloprotease inducer in laryngeal squamous cell carcinoma. Laryngoscope 113:1406-1410. doi:10.1097/00005537-200308000-00027

15. Gu ZD, Chen KN, Li M, Gu J, Li JY (2005) Clinical significance of matrix metalloproteinase- 9 expression in esophageal squamous cell carcinoma. World J Gastroenterol 11:871-874

16. Reimers N, Zafrakas K, Assmann V, Egen C, Riethdorf L, Riethdorf S, Berger J, Ebel S, Janicke F, Sauter G, Pantel K (2004) Expression of extracellular matrix metalloproteases inducer on micrometastatic and primary mammary carcinoma cells. Clin Cancer Res 10:3422-3428. doi:10.1158/1078-0432.CCR-03-0610

17. Davidson B, Goldberg I, Berner A, Kristensen GB, Reich R (2003) EMMPRIN (extracellular matrix metalloproteinase inducer) is a novel marker of poor outcome in serous ovarian carcinoma. Clin Exp Metastasis 20:161-169

18. Sier CF, Zuidwijk K, Zijlmans HJ, Hanemaaijer R, Mulder-Stapel AA, Prins FA, Dreef EJ, Kenter GG, Fleuren GJ, Gorter A (2006) EMMPRIN-induced MMP-2 activation cascade in human 
cervical squamous cell carcinoma. Int J Cancer 118:2991-2998. doi:10.1002/ijc. 21778

19. Tsai WC, Chao YC, Lee WH, Chen A, Sheu LF, Jin JS (2006) Increasing EMMPRIN and matriptase expression in hepatocellular carcinoma: tissue microarray analysis of immunohistochemical scores with clinicopathological parameters. Histopathology 49:388-395. doi:10.1111/j.1365-2559.2006.02516.x

20. Tsai WC, Sheu LF, Nieh S, Yu CP, Sun GH, Lin YF, Chen A, Jin JS (2007) Association of EMMPRIN and fascin expression in renal cell carcinoma: correlation with clinicopathological parameters. World J Urol 25:73-80. doi:10.1007/s00345-0060110-2

21. van der Jagt MF, Sweep FC, Waas ET, Hendriks T, Ruers TJ, Merry AH, Wobbes T, Span PN (2006) Correlation of reversioninducing cysteine-rich protein with kazal motifs (RECK) and extracellular matrix metalloproteinase inducer (EMMPRIN), with MMP-2, MMP-9, and survival in colorectal cancer. Cancer Lett 237:289-297. doi:10.1016/j.canlet.2005.06.009

22. Nabeshima K, Suzumiya J, Nagano M, Ohshima K, Toole BP, Tamura K, Iwasaki H, Kikuchi M (2004) Emmprin, a cell surface inducer of matrix metalloproteinases (MMPs), is expressed in T-cell lymphomas. J Pathol 202:341-351. doi:10.1002/path.1518

23. Gu J, Zhang C, Chen R, Pan J, Wang Y, Ming M, Gui W, Wang D (2009) Clinical implications and prognostic value of EMMPRIN/CD147 and MMP2 expression in pediatric gliomas. Eur J Pediatr 168:705-710. doi:10.1007/s00431-008-0828-5

24. Sameshima T, Nabeshima K, Toole BP, Yokogami K, Okada Y, Goya T, Koono M, Wakisaka S (2000) Expression of emmprin (CD147), a cell surface inducer of matrix metalloproteinases, in normal human brain and gliomas. Int J Cancer 88:21-27

25. Hueng DY, Lin GJ, Huang SH, Liu LW, Ju DT, Chen YW, Sytwu HK, Chang C, Huang SM, Yeh YS, Lee HM, Ma HI (2011) Inhibition of Nodal suppresses angiogenesis and growth of human gliomas. J Neurooncol 104:21-31. doi:10.1007/s11060010-0467-3

26. Phillips HS, Kharbanda S, Chen R, Forrest WF, Soriano RH, Wu TD, Misra A, Nigro JM, Colman H, Soroceanu L, Williams PM, Modrusan Z, Feuerstein BG, Aldape K (2006) Molecular subclasses of high-grade glioma predict prognosis, delineate a pattern of disease progression, and resemble stages in neurogenesis. Cancer Cell 9:157-173. doi:10.1016/j.ccr.2006.02.019

27. Schulte A, Gunther HS, Phillips HS, Kemming D, Martens T, Kharbanda S, Soriano RH, Modrusan Z, Zapf S, Westphal M, Lamszus K (2011) A distinct subset of glioma cell lines with stem cell-like properties reflects the transcriptional phenotype of glioblastomas and overexpresses CXCR4 as therapeutic target. Glia 59:590-602. doi:10.1002/glia.21127

28. Louis DN, Ohgaki H, Wiestler OD, Cavenee WK, Burger PC, Jouvet A, Scheithauer BW, Kleihues P (2007) The 2007 WHO classification of tumours of the central nervous system. Acta Neuropathol 114:97-109. doi:10.1007/s00401-007-0243-4
29. Fuhrman SA, Lasky LC, Limas C (1982) Prognostic significance of morphologic parameters in renal cell carcinoma. Am J Surg Pathol 6:655-663

30. Lee CC, Jan HJ, Lai JH, Ma HI, Hueng DY, Lee YC, Cheng YY, Liu LW, Wei HW, Lee HM (2010) Nodal promotes growth and invasion in human gliomas. Oncogene 29:3110-3123. doi: 10.1038/onc. 2010.55

31. Ma HI, Chiou SH, Hueng DY, Tai LK, Huang PI, Kao CL, Chen YW, Sytwu HK (2011) Celecoxib and radioresistant glioblastoma-derived CD133+ cells: improvement in radiotherapeutic effects. Laboratory investigation. J Neurosurg 114:651-662. doi: 10.3171/2009.11.JNS091396

32. Jan HJ, Lee CC, Shih YL, Hueng DY, Ma HI, Lai JH, Wei HW, Lee HM (2010) Osteopontin regulates human glioma cell invasiveness and tumor growth in mice. Neuro-oncology 12:58-70. doi:10.1093/neuonc/nop013

33. Harley CB, Futcher AB, Greider CW (1990) Telomeres shorten during ageing of human fibroblasts. Nature 345:458-460. doi: $10.1038 / 345458 \mathrm{a} 0$

34. Reichenbach P, Hoss M, Azzalin CM, Nabholz M, Bucher P, Lingner J (2003) A human homolog of yeast Est1 associates with telomerase and uncaps chromosome ends when overexpressed. Curr Biol 13:568-574

35. Kim SK, Wang KC, Cho BK, Lim SY, Kim YY, Oh CW, Chung YN, Kim CY, Lee CT, Kim HJ (2003) Adenoviral p16/CDKN2 gene transfer to malignant glioma: role of p16 in growth, invasion, and senescence. Oncol Rep 10:1121-1126

36. Li H, Chen J, He M, Hui XH, Cai BW, Li Y (2007) Expression of CD147 and MMP-2 in human gliomas and its correlations with prognosis. Sichuan da xue xue bao Yi xue ban 38:396-399

37. Ho DM, Hsu CY, Ting LT, Chiang H (2002) Histopathology and MIB-1 labeling index predicted recurrence of meningiomas: a proposal of diagnostic criteria for patients with atypical meningioma. Cancer 94:1538-1547

38. Rath P, Miller DC, Litofsky NS, Anthony DC, Feng Q, Franklin C, Pei L, Free A, Liu J, Ren M, Kirk MD, Shi H (2011) Isolation and characterization of a population of stem-like progenitor cells from an atypical meningioma. Exp Mol Pathol 90:179-188. doi: 10.1016/j.yexmp.2010.12.003

39. Kalamarides M, Stemmer-Rachamimov AO, Niwa-Kawakita M, Chareyre F, Taranchon E, Han ZY, Martinelli C, Lusis EA, Hegedus B, Gutmann DH, Giovannini M (2011) Identification of a progenitor cell of origin capable of generating diverse meningioma histological subtypes. Oncogene 30:2333-2344. doi: 10.1038/onc.2010.609

40. Hueng DY, Sytwu HK, Huang SM, Chang C, Ma HI (2011) Isolation and characterization of tumor stem-like cells from human meningiomas. J Neurooncol 104:45-53. doi:10.1007/ s11060-010-0469-1

41. Chiu SH, Wang ID, Sytwu HK, Hueng DY (2013) Atypical meningioma. J Neurosurg 118:912-913. doi:10.3171/2012.11.JNS121838 